\title{
Lack of the Age-Dependent Alteration in Mokuboito
}

\section{(Mu-Fang-Yi-Tang)}

\author{
Hiroyasu Satoh $^{1}$ and Seiichiro Nishida ${ }^{2}$ \\ 1. Department of Health Science, Shitennoji University, Osaka 583-8501, Japan \\ 2. Department of Pharmacology, Division of Traditional Herbal Medicine, Nara Medical University, Nara 634-8521, Japan
}

\begin{abstract}
Objective: To compare the age-dependent vasodilating actions of Mokuboito, a kind of Kampo formulations, its ingredients. Methods: Rat aorta ring strips by pretreatment with $5 \mu \mathrm{M}$ NE were used. Results: Sinomenine (a major constituent in Sinomenine acutum) at $100 \mu \mathrm{M}$ dilated NE-induced vasoconstriction by $68.8 \pm 5.2 \%(\mathrm{n}=6, \mathrm{P}<0.01)$ in 10 -weeks old rats, but only by $18.6 \pm 1.5 \%$ (n $=6, \mathrm{P}<0.01)$ in 65 -weeks old rats. Sinomenine acutum (a main ingredient of Mokuboito) $(0.3-3 \mathrm{mg} / \mathrm{ml}$ ) showed only vasodilatations in 10 - and 35 -weeks old rats; at $3 \mathrm{mg} / \mathrm{ml}$ by $96.7 \pm 4.8 \%(\mathrm{n}=7, \mathrm{P}<0.01)$ in 10-weeks old rats. In 65 -weeks old rats, however, Sinomenine acutum at low concentrations $(0.03-0.3 \mathrm{mg} / \mathrm{ml})$ constricted the aorta. The vasodilatation at $3 \mathrm{mg} / \mathrm{ml}$ was attenuated to $46.0 \pm 5.7 \%(\mathrm{n}=6$, $\mathrm{P}<0.01)$. Mokuboito also exerted the vasodilatation in all aged rats, although at low concentrations exhibited the vasoconstriction in higher aged rats. Mokuboito at $3 \mathrm{mg} / \mathrm{ml}$ dilated aorta by $98.9 \pm 2.8 \%(\mathrm{n}=7, \mathrm{P}<0.01)$ in 10 -weeks and by $97.5 \pm 13.5 \%(\mathrm{n}=6, \mathrm{P}<0.01)$ in 65-weeks old rats. Conclusion: Mokuboito, Sinomenine acutum (multiple compounds) and sinomenine (single compound) by themselves had the potent vasodilating actions. Sinomenine acutum- and sinomenine-induced vasodilatations decreased along with ageing, but Mokuboito as a mixture has less or no effect on the age-dependent attenuation in any aged rats. Herbal drugs including plenty ingredients exert more effective actions for higher aged rats.
\end{abstract}

Key words: Mokuboito, sinomenine acutum, sinomenine, vasodilatation, age-dependent attenuation.

\section{Introduction}

Mokuboito (Mu-Fang-Yi-Tang), a kind of Kampo formulations, has been traditionally used as an indication for patients with the symptoms including wheezing, dark complexion and deep tight pulse. It has been reported that Mokuboito improves heart failure symptoms accompanied by plasma brain natriuretic peptide (BNP) concentration, and reduces the rank of NYHA classification [1]. Satoh [2] has demonstrated that Mokuboito, Sinomenine acutum and sinomenine possess cardiac electropharmacological actions and exert conservative effects on cardiomyocytes. As a result, Mokuboito and its ingredients can improve the cardiac functions under the chronic heart failure. Furthermore, we have already demonstrated that Mokuboito and the ingredients dilate rat aorta, not only

Corresponding author: Hiroyasu Satoh, professor, research fields: pharmacology.E-mail: hysat@shitennoji.ac.jp. due to endothelium-dependent mechanisms (NO and $\mathrm{PGI}_{2}$ ) but also due to modulation of $\mathrm{Ca}^{2+}$ channel and PK-C activity [3, 4]. Thus, Mokuboito regulates the tone of blood vessels and adjusts the blood pressure and flow.

Mokuboito consists of $4 \mathrm{~g}$ Sinomeni Caulis et Rhizoma (rhizome of Sinomenine acutum Rehdler et Wilson), $3 \mathrm{~g}$ Cinnamomi Cortex (bark of Cinnamomum cassia Blume), $3 \mathrm{~g}$ Ginseng radix (roots of Panax ginseng) and $10 \mathrm{~g}$ Gypsum Fibrosum. As a modulator of body's fluid, Sinomenine acutum (a vine plant) is a pain killer and has been applied for disturbance of body fluids and Rheumatic diseases [5]. Sinomenine contained in Sinomeni acutum is an alkaloid [5, 6], and exhibits various pharmacological effects such as anti-inflammatory [7] and immuno-modulative actions [8]. Thus, Mokuboito may also be used for clinical treatment of Rheumatoid arthritis $[6,9]$. 
Chronic heart failure occurs more frequently in elderly persons. Ageing produces various physiological and pathological deleterious changes such as plaque formation in vascular systems. Simultaneously, the age-dependent modulation of ion channels and signal transduction pathways might be caused in the endothelium and smooth muscle cells. Thus, the pharmacological effects of the drugs on cardiovascular system may also be modulated with ageing. It has been reported that endothelium-dependent relaxation is attenuated in aged rat aorta [3, 4, 10-13]. The relaxation induced by ACh is impaired in the aortic rings obtained from old female rats [14]. From direct in situ measurement of NO in rat aorta, the NO-release diminishes further in advanced aged rats. L-NAME, a NO-synthesis inhibitor, attenuates ACh-induced vasodilatation. These results indicate that the NO-dependent vasodilatation is reduced in advance with ages.

Similaly, the inhibitory effect of a $\mathrm{Ca}^{2+}$ channel blocker (israpidine) on NE-induced contraction decreases with ageing from 3 to 10 weeks, but increases with ageing from 10 to 40 weeks [15]. $\beta$-adrenoceptor mediated relaxation decreases with age in rat aorta and various vascular beds of many species [16]. In rat pulmonary artery, however, the density of specific binding sites for $\mathrm{Ca}^{2+}$ channel antagonist (nicardipine) is not different between adult ( 6 months) and young (1-3 months) rats [17]. The lack of age-dependent alteration is also observed in rat femoral artery [18]. Thus, it is controversial for the age-dependent effects of drugs. It is still unknown yet whether the vasodilatations induced by herbal medicines (Mokuboito and its ingredients) are modulated with ageing. For the age-related alterations of Mokuboito (mixture)-, Sinomenine acutum (multiple compounds)- and sinomenine (single compound)-induced vasodilatations, therefore, we examined to compare the vasodilating effects under the same conditions using the aorta ring strips of different aged rats.

\section{Material and Methods}

All experiments were carried out, according to the guidelines laid down by the Nara Medical University Animal Welfare Committee, and also under the terms of the Declaration of Helsinki.

Male Wistar rats (10-, 35- and 65-weeks-old) were anesthetized with ether, and euthanized by exsanguinations, as described [3, 4]. The thoracic aorta was quickly removed, and the isolated aorta was cut into rings of 3-mm in length. The rings were suspended between two triangular-shaped stainless steel stirrups in a jacketed organ chamber filled with $20 \mathrm{ml}$ modified Krebs-Henseleit solution. The modified Krebs-Henseleit solution was comprised of, in $\mathrm{mM}$ : $118 \mathrm{NaCl}, 4.6 \mathrm{KCl}, 1.2 \mathrm{MgSO}_{4}, 1.2 \mathrm{KH}_{2} \mathrm{PO}_{4}, 11.1$ glucose, $\quad 27.2 \quad \mathrm{NaHCO}_{3}, \quad 0.03$ $\mathrm{Na}_{2}$-ethylnediaminetetraacetic acid (EGTA), and 1.8 $\mathrm{CaCl}_{2}$. The chamber solution was kept at $36.5^{\circ} \mathrm{C}$ and oxygenated with $95 \% \mathrm{O}_{2}$ and $5 \% \mathrm{CO}_{2}$. The lower stirrup was anchored and the upper stirrup was attached to a force-displacement transducer (Nihon Kohden TB-652T, Tokyo, Japan) to record the isometric force. All rings were stretched to generate a resting tension of $1.2 \mathrm{~g}$. which was optimal for contractions with $\alpha$-adrenergic receptor agonist. After $40 \mathrm{~min}$ of resting, NE $(5 \mu \mathrm{M})$ was added to the tissue bath. After the contractile response became steady, the drugs were cumulatively administrated into the bath solution. The effects of each concentration of the drugs were measured 6-10 min after the responses became steady. The relaxation response was analyzed as a percentage decrease from the maximal contraction induced by NE.

The drugs used were Mokuboito, Sinomenine acutum and sinomenine. Sinomenine acutum was prepared as a spray-dried powder extracted with boiling water of ground raw material of Sinomoneni Caulis et Rhizoma (rhizome of Sinomenine acutum Rehdler et Wilson). Mokuboito is supplied from Tsumura Co. as a spray-dried powder which was extracted with boiling water of a mixture of $4 \mathrm{~g}$ Sinomeni Caulis et Rhizoma (rhizome of Sinomenine 
acutum Rehdler et Wilson), 3 g Cinnamomi Cortex (bark of Cinnamomum cassia Blume), $3 \mathrm{~g}$ Ginseng radix (roots of Panax ginseng) and $10 \mathrm{~g}$ Gypsum Fibrosum. These drugs (products) contain the same contents of active ingredients by the analysis of 3D-HPLC. This extract is equivalent to TJ-36 provided from Tsumura Co. for clinical use. Sinomenine (7,8-didehydro-4-hydrxy-3,7-dimethoxy-17-methyl-9 $\alpha, 13 \alpha, 14 \alpha$-morphinan-6-one)(Wako Pure Chemical Ltd., Osaka, Japan) was also used.

All values are represented as the means \pm S.E.M. The differences of data in mean values were analyzed by the Student $t$-test and ANOVA, and a p value of less than 0.05 was considered significant.

\section{Results}

\subsection{Vasorelaxation Induced by Mokuboito}

Application of NE caused the remarkable vasoconstrictions on resting aorta. Mokuboito dilated it concentration-dependently. In 10-weeks rats, Mokuboito at $0.03-3 \mathrm{mg} / \mathrm{ml}$ significantly relaxed rat aorta; at $3 \mathrm{mg} / \mathrm{ml}$ by $98.9 \pm 2.8 \%(\mathrm{n}=7, \mathrm{P}<0.01)($ Fig. 1A). In 35 -weeks rats, Mokuboito at $0.03 \mathrm{mg} / \mathrm{ml} \mathrm{did}$
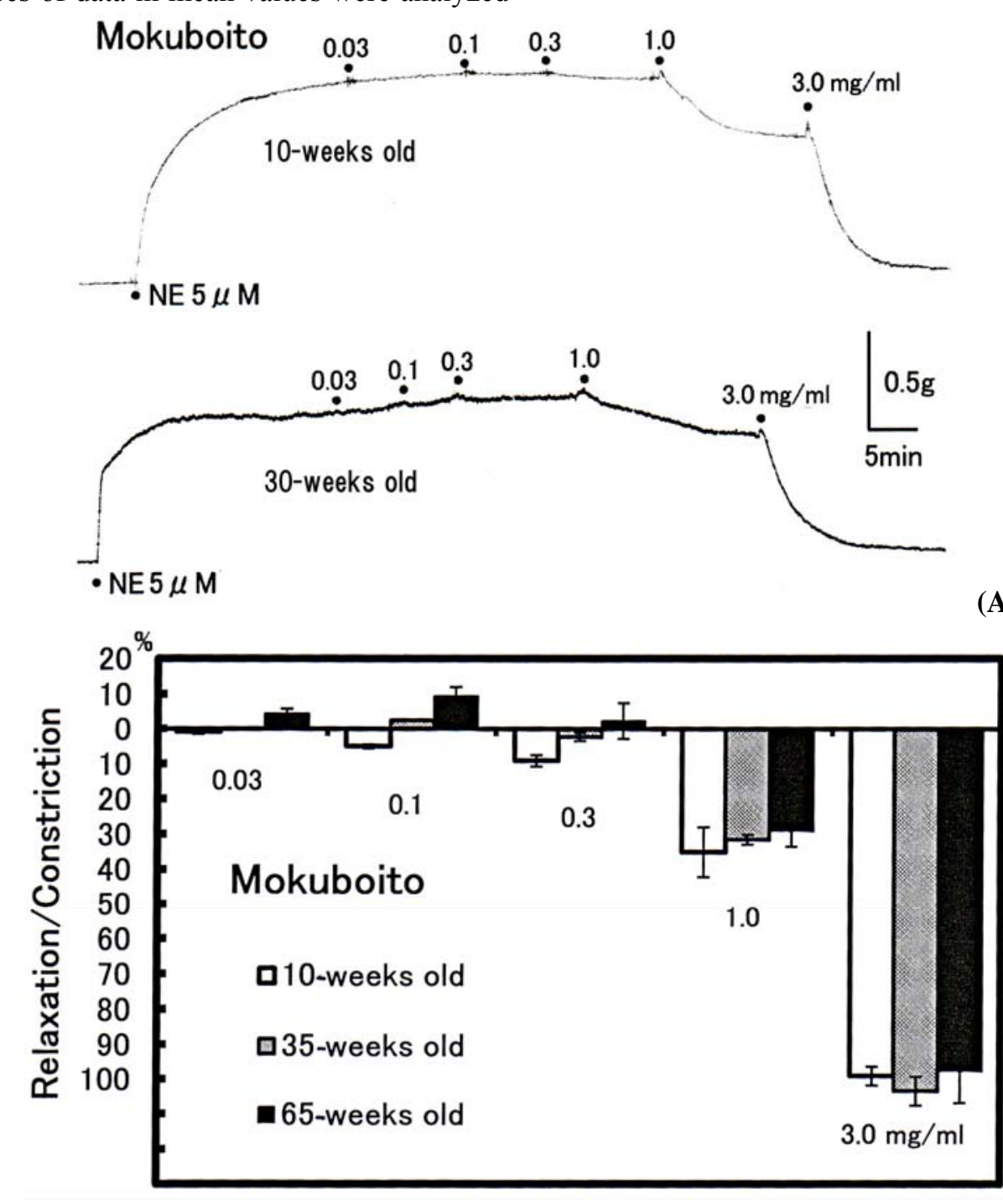

(A)

(B)

Fig. 1 Vasomodulations by Mokuboito on NE-induced vasoconstriction. A: Vasoconstriction and vasodilation in 10- and 65-weeks old rats. B: Age-dependent modulation induced by Mokuboito of the vascular tone in 10-, 35- and 65-weeks old rats. White columns mean 10 -weeks old rats $(n=7)$ as a control, gray columns are in 35-weeks old rats $(n=6)$, and black columns are 65-weeks old rats $(\mathrm{n}=6)$. Values $(\%)$ represent mean $\pm S E M$. $* *: P<0.01$, with respect to control value (10-weeks old rats). 


\section{Sinomenine acutum}
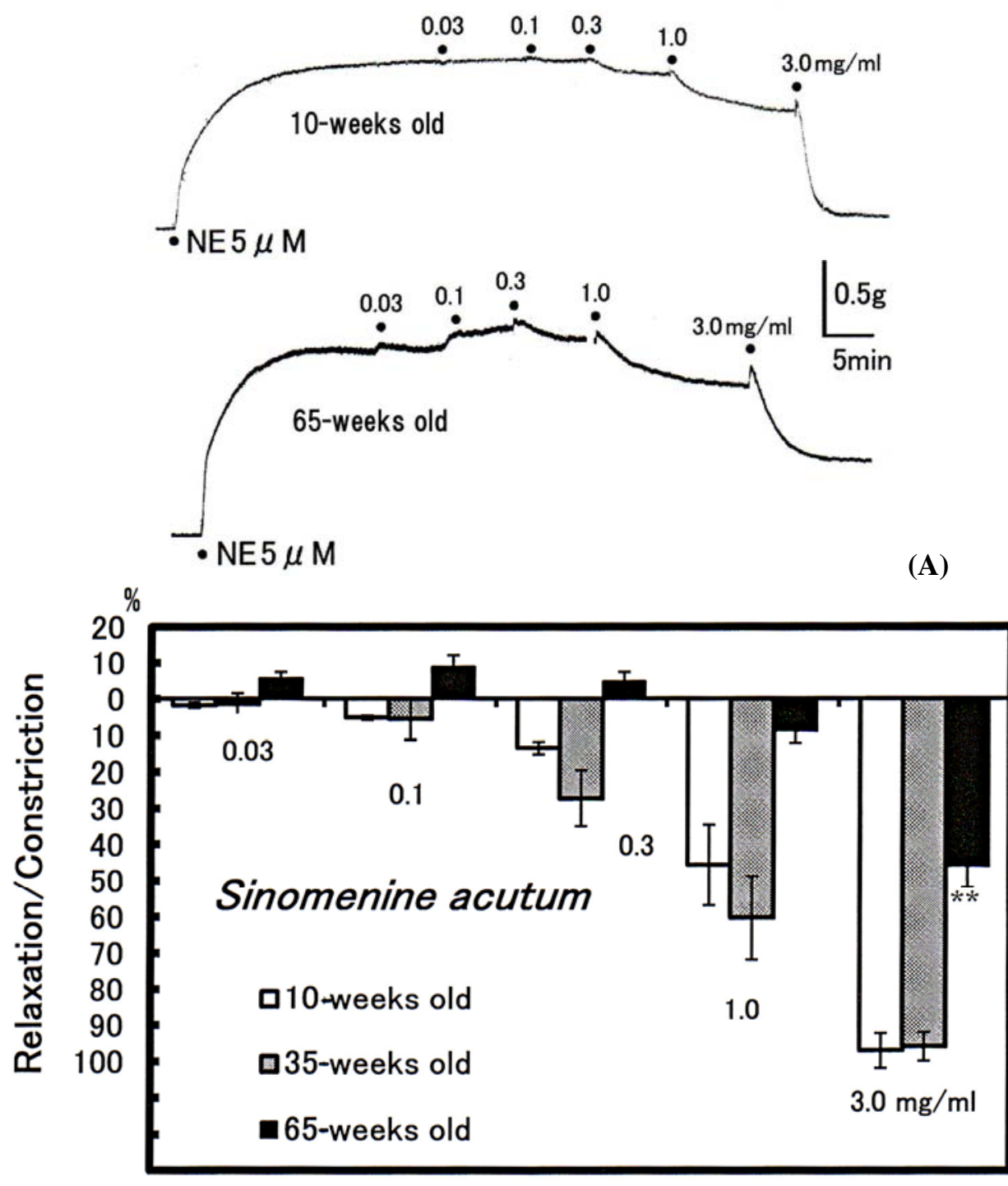

(B)

Fig. 2 Vasodilations on NE-induced vasoconstriction. A: Vascular effects of Sinomenine acutum in 10- and 65-weeks old rats. B: Age-dependent vasodilatations of Sinomenine acutum in 10-, 35- and 65-weeks old rats. White columns mean 10-weeks old rats $(n=7)$ as a control, gray columns are in 35 -weeks old rats $(n=6)$, and black columns are 65 -weeks old rats $(n=6)$. Values (\%) represent mean \pm SEM. $* *: P<0.01$, with respect to control value (10-weeks old rats).

not cause any effects, and at $0.1 \mathrm{mg} / \mathrm{ml}$ constricted by $2.5 \pm 1.2 \%(\mathrm{n}=6, \mathrm{P}<0.05)$. At higher concentrations $(0.3-3 \mathrm{mg} / \mathrm{ml})$ Mokuboito dilated the aorta in 35-weeks rats. At $0.3 \mathrm{mg} / \mathrm{ml}$, the vasodilatation was more markedly in 10-weeks than in 35-weeks old rats. Mokuboito at 1 to $3 \mathrm{mg} / \mathrm{ml}$ dilated it but not significantly. In 65-weeks rats, Mokuboito at low concentrations $(0.03-0.3 \mathrm{mg} / \mathrm{ml})$ constricts the aorta, and at high concentrations ( 1 and $3 \mathrm{mg} / \mathrm{ml}$ ) exerts potent vasodilatation. The vasodilatations at $3 \mathrm{mg} / \mathrm{ml}$ were $98.9 \pm 2.8 \%(\mathrm{n}=7), 100 \pm 3.8 \%(\mathrm{n}=6)$ and $97.5 \pm 13.5 \%(\mathrm{n}=6)$ in 10 -, 35 - and 65 -weeks old rats, respectively. But there was no significant difference among the age-dependent vasodilatations (Fig. 1B).

\subsection{Vasodilatation Induced by Sinomenine Acutum}

Sinomenium acutum $(0.03-3 \mathrm{mg} / \mathrm{ml})$ also dilated rat aorta concentration-dependently in 10-weeks old rats; at $3 \mathrm{mg} / \mathrm{ml}$ by $96.9 \pm 4.8 \%(\mathrm{n}=6, \mathrm{P}<0.01)$ (Fig. $2 \mathrm{~A})$. In 35-weeks old rats, Sinomenine acutum also dilated the 


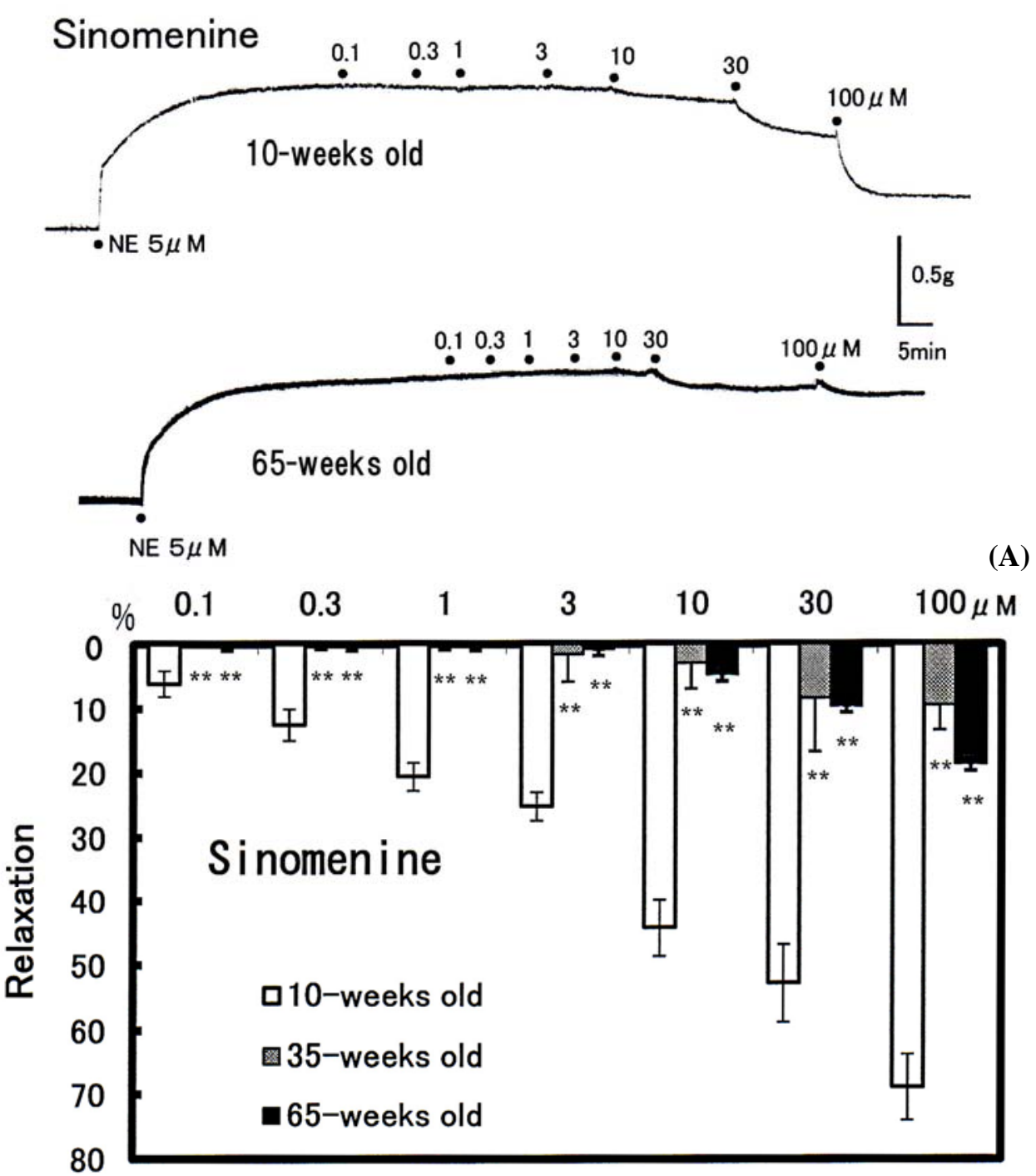

(B)

Fig. 3 Different effects of sinomenine in 10- and 65-weeks old rats. A: Vasodilations on NE-induced vasoconstriction. B: Age-dependent alteration of the vasodilatation induced by sinomenine in 10-, 35- and 65-weeks old rats. White columns mean 10 -weeks old rats $(n=6)$ as a control, gray columns are in 35-weeks old rats $(n=6)$, and black columns are 65 -weeks old rats $(n$ = 6). Values (\%) represent mean \pm SEM. **: $P<0.01$, with respect to control value (10-weeks old rats).

aorta; at $3 \mathrm{mg} / \mathrm{ml}$, by $95.8 \pm 3.8 \%(\mathrm{n}=6, \mathrm{P}<0.01)$. The vasodilatation (at $0.3-1.0 \mathrm{mg} / \mathrm{ml}$ ) was weaker in 35 -weeks than in 10-weeks old rats (but not significantly). In 65-weeks old rats, Sinomenine acutum at low concentrations $(0.03-0.3 \mathrm{mg} / \mathrm{ml})$ exerted weak constrictions like Mokuboito. The peak constriction at $0.1 \mathrm{mg} / \mathrm{ml}$ was $8.9 \pm 3.3 \%(\mathrm{n}=6, \mathrm{P}<$ $0.05)$. Sinomenine acutum at $3 \mathrm{mg} / \mathrm{ml}$ caused the vasodilatation by $46.0 \pm 5.7 \%(\mathrm{n}=6, \mathrm{P}<0.01)$, which was the smallest vasodilatation in all aged rats (Fig. 2B).

\subsection{Vasorelaxations Induced by Sinomenine}

Sinomenine also dilated the aorta concentration-dependently. In younger rats (10-weeks old rats), $100 \mu \mathrm{M}$ sinomenine strongly dilated the aorta by $68.8 \pm 5.1 \%(\mathrm{n}=6, \mathrm{P}<0.01)$ (Fig. $3 \mathrm{~A})$. However, the potency of sinomenine-induced vasodilatation markedly decreased with ageing. In 35- 
and 65-weeks old rats, the vasodilatation at low concentrations $(0.1-3 \mu \mathrm{M})$ became to be almost abolished with ageing. In 35-weeks rats, the vasodilatation was just $9.3 \pm 4.0 \%(\mathrm{n}=6, \mathrm{P}<0.01)$ even at high concentration $(100 \mu \mathrm{M})$ (Fig. 3B). In 65-weeks old rats, the vasodilatation induced by sinomenine (100 $\mu \mathrm{M})$ was slightly recovered as compared with that in 35-weeks old rats. However, the vasodilatation in 65 -weeks rats was only $18.6 \pm 1.5 \%(n=6, P<0.01)$, and was so much weaker than that in 10 -weeks old rats.

\section{Discussion}

The present experiments showed that Mokuboito, Sinomenine acutum extract and sinomenine caused vasodilatation on the constricted rat aorta. The sinomenine- and Sinomenine acutum-induced vasodilatations were markedly attenuated along with ageing. Sinomeine acutum at low concentration $(0.3$ $\mathrm{mg} / \mathrm{ml}$ ) constricted the aorta, but at $3 \mathrm{mg} / \mathrm{ml}$ exerted the vasodilatation in aged rat. The vasodilatation induced by Sinomenine acutum significantly decreased with ageing. Mokuboito at low concentrations also constricted the aorta in aged rats. The Mokuboito-induced vasorelaxation was age-dependent. At high concentrations, however, the vasodilatations never decreased in advance with age.

Advance of ages induces serious vascular changes. It has been found that endothelium-dependent relaxation is attenuated with ageing. The relaxation induced by $\mathrm{ACh}$ is impaired in aortic rings of old female rats [14]. $\mathrm{NO}$ availability and NO-release are also diminished in the aorta of aged female rats. L-NAME attenuates the ACh-induced vasodilatation, but fails to affect it in aged rat aorta. Thus, NO-dependent mechanism might be minor contribution to the vasodilatation in aged rats.

Simultaneously ageing may also modulate ion channels, cellular signal transductions and receptor-mediated transduction in smooth muscles. $\mathrm{Ca}^{2+}$ channel exhibits age-dependent alteration, although it plays a major role in the constriction of smooth muscle cells. The dilating effects of isradipine
$\left(\mathrm{Ca}^{2+}\right.$ channel antagonist) increased in the thoracic aorta of aged rat [15]. However, the density of specific binding sites for nicardipine $\left(\mathrm{Ca}^{2+}\right.$ channel antagonist) in rat pulmonary artery is not altered between adult ( 6 months) and young (1-3 months) rats [17], consistent with no age-dependent alteration in rat femoral artery [18]. In addition, the vasorelaxation mediated through $\beta$-adrenoceptor also decreases with ageing in rat aorta and in vascular beds of many species [16].

Under the conditions in advanced with ageing, thus, the pharmacological effects of the drugs on vascular system may be modulated. Mokuboito dilates vessels due to endothelium-dependent mechanisms and also due to the regulation of ion channels $\left(\mathrm{Ca}^{2+}\right.$ channel), PKC activity and $\beta$-adrenoceptor stimulation [3, 4], accompanied with the age-dependent alterations of pharmacological mechanisms. The Mokuboito's ingredients-induced vasodilatations are mediated through almost the same mechanisms. In the present experiments, the vasodilatation induced by sinomenine inevitably decreased in aged rats. The effects of Sinomenin acutum were similarly modulated with ageing. The alteration of Sinomenine acutum (including more ingredients)-induced effects may be more complicated than that of sinomenine. Sinomenine acutum at low concentrations caused quite different effect (the vasoconstriction) in high aged rats (65-weeks old). The vasodilatation induced by Sinomenine acutum was produced more markedly in aged rats, as compared with sinomenine. At lower concentrations, Mokuboito as a mixture constricted the aorta in aged rats. And at higher concentrations, Mokuboito never attenuated the vasodilatation along with ageing. The similar phenomenon has already been observed in our previous studies [13]. Ginkgo biloba extract (GBE) is one of the famous herbal medicine [19, 20] and is useful for the diseases such as ischemic brain injury [21, 22] and cerebrovascular insufficiency [23]. Both GBE and bilobalide (its main constituent) have potent vasodilating effects [12]. The vasodilatation 
induced by bilobalide decreased, but that by GBE (a mixture) did not decrease with ageing [13]. GBE contains multiple content alkaloid and flavonoids [11]. These results suggest that the complicated interactions among the ingredients can produce constitutive effects of GBE. Therefore, we infer that the complicated interactions among the ingredients would contribute to the effective pharmacological stability against the age-dependent alterations.

The basic treatment strategy of heart failure consists of (1) reducing workload of heart, (2) protection of cardiomyocytes, and (3) restriction and control of waters and sodium. In order to reduce the preload and afterload, the dilation of arterioles and veins are required in the case of elevated filling pressures and reduced cardiac output. Controlling both of the loads is the essential therapeutic strategies for heart failure. Thus, the vasodilating action of Mokuboito is expected to regulate both the preload and afterload in chronic heart failure. On the contrary, when vascular tone is excessive low under the bacterial or ischemic shock, Mokuboito would constrict the vessels to maintain blood flow. Furthermore, chronic heart failure is related closely with plaque formation. But there is no information whether or not Mokuboito and the ingredients modulate lipid metabolism.

Mokuboito is composed of four crude herbal drugs. Sinomenine acutum, Cinnamomi cortex [24] and Ginseng radix [25] have also vasodilating effects. And each ingredient (herbal drug) also contains many kinds of chemical compounds. Therefore, the resultant effect of Mokuboito is exhibited as a net of the complicated interactions among a lot of contained ingredients. As a single compound, the sinomenine-induced vasodilatation decreased along with ageing as same as bilobalide in GBE. The pharmacological effects of just single compound are attenuated in advance with ageing. On the other hand, Sinomenine acutum (multiple compounds) suppresses the age-dependent attenuation of vasodilating action, and Mokuboito (as a mixture) maintains the marked action. Mokuboito contains numerous constituents, and sinomenine and the other constituents by themselves contribute to the Mokuboito-induced vasodilatation mediated through their interactions. The interactions among the ingredients play an important role for the pharmacological actions of herbal medicines. In this study, therefore, the interactions may produce more effective pharmacological stability of Mokuboito against the age-dependent alterations. The effects of Mokuboito and the ingredients on peripheral vessels are still unclear, as limitation of the experiments. As a side effect, it is known that Sinomenine acutum possesses aristolochic acid, which may cause kidney disfunctions by its renal toxity. Further studies are needed to elucidate in more detail mechanisms.

\section{Acknowledgements}

The authors wish to express thanks for the supply of Mokuboito extract and Sinomenine acutum (Tsumura Co.).

\section{References}

[1] S. Yakubu, Y. Kinoshita, Y. Arakawa, M. Takahashi and S. Kitanaka, Clinical evaluation of Mokuboito (Mu-Fang-Yi-Tang): A Japanese and Chinese traditional medicine for heart failure, J. Trad Med. 19 (2002) 159-163.

[2] H. Satoh, Electropharmacology of Sinomeni caulis et rhizome and its constituents in cardiomyocytes, Am J. Chin Med. 33 (2005) 967-979.

[3] S. Nishida and H. Satoh, In vitro pharmacological actions of sinomenine on the smooth muscle and the endothelial cell activity in rat aorta, Life Sci. 79 (2006) 1203-1206.

[4] S. Nishida and H. Satoh, Vascular pharmacology of Mokuboito (Mu-Fang-Yi Tang) and its constituents on the smooth muscle and the endothelium in rat aorta, Evi Comp Alter Med. 4 (2007) 335-341.

[5] Y. Li, S. Cui, Y. Cheng, X. Chen and Z. Hu, Application of nonaqueous capillary electrophoresis for quantitative analysis of quinolizidine alkaloids in chinese herbs, Anal Chim Acta 508 (2004) 17-22.

[6] H. Yamasaki, Pharmacology of sinomenine, an anti-rheumatic alkaloids from Sionomenine acutum, Acta Med Okayama 30 (1976) 1-20.

[7] L. Liu, J. Riese, K. Resch and V. Kaever, Impairment of macropharge eicosanoids and nitric oxide production by 
alkaloid from Sinomenium acutum, Arzneimit Forsch 44 (1994) 1223-1226.

[8] W. Mark, S. Schneeberger, R. Seiler, D. M. Stroke, A. Amberger, F. Offner, D. Candinas and R. Margreiter, Sinomenine blocks tissue remodeling in a rat model of chronic cardiac allograft rejection, Transplant 15 (2003) 940-945.

[9] L. Liu, E. Buchner, D. Beitze, C. B. Schmidt-Weber, V. Kaever, F. Emmrich, R. W. Kinne, Amelioration of rat experimental arthritides by treatment with the alkaloid sinomenine, Internat J Immunopharmacol 18 (1996) 529-543.

[10] H. Satoh, Effects of Ginkgo biloba extract and bilobalide, a main constituent, on the ionic currents in guinea pig ventricular cardiomyocytes, Arzneimit Forsch 53 (2003) 407-413.

[11] S. Nishida and H. Satoh, Comparative vasodilating actions among terpenoids and flavonoids contained in Ginkgo biloba extract, Clin Chim Acta 339 (2004) 129-133.

[12] S. Nishida and H. Satoh, Mechanisms for the vasodilations induced by Ginkgo biloba extract and its main constituent, bilobalide, in rat aorta, Life Sci. 72 (2003) 2659-2667.

[13] S. Nishida and H. Satoh, Age-related change in the vasodilating actions of Ginkgo biloba extract and its main constituent, bilobalide, in rat aota, Clin Chim Acta 354 (2005) 141-146.

[14] M. R. Tschudi, M. Barton, N. A. Bersinger, P. Moreau, F. Cosentino, G. Noll, T. Malinsli, T. F. Luscher, Effect of age on kinetics of nitric oxide release in rat aorta and pulmonary artery, J. Clin. Invest 98 (1996) 899-905.

[15] M. Satoh, S. Kanai, N. Ashikawa and I. Takayanagi, Age-related alteration of alpha(1)-adrenoceptor mechanisms and $\mathrm{Ca} 2+$ inhibitory effects of isradipine, Arch InterPharmacodyn Therapeut 330 (1995) 190-205.

[16] K. B. Kang, M. A. Rajanayagam, A. V. Zypp and H. Majewski, A Role for cyclooxygenase in aging-related changes of beta-adrenoceptor-mediated relaxation in rat aortas, Naunyn-Schmied Arch Pharmacol 375 (2007) 273-281.

[17] A. Ricci, E. Bronzetti, D. E. Assouad, L. Felici, S. Greco and S. Mariotta, Influence of age on L-type Ca2+ channels in the pulmonary artery and vein of spontaneously hypertensive rats, Mech Age Develop 120 (2000) 33-44.

[18] E. E. Soltis, Effects of age on blood pressure and membrane-dependent vascular responses in the rat, Circ Res 61 (1987) 889-897.

[19] J. M. Dennis, J. Kenneth and H. Kerry, Efficacy, safety, and use of Ginkgo biloba in clinical and preclinical applications, Alternat Ther 7 (2001) 70-90.

[20] B. J. Diamond, S. C. Shiflett and N. E. Schoenberger, Ginkgo biloba extract: Mechanisms and clinical indications, Arch Phys Med Rehab 81 (2000) 668-678.

[21] J. Kleijnen and P. Knipschild, Ginkgo biloba for cerebral insufficiency, Br J Clin Pharmacol 34 (1992) 352-358.

[22] W. R. Zhang, T. Hayashi, H. Kitagawa, C. Sasaki, K. Sakai and H. Warita, Protective effects of Ginkgo biloba extract on rat brain with transient middle cerebral artery occlusion, NeurolRes 22 (2000) 517-521.

[23] J. Vesper and K. D. Hänsegen, Efficacy of Ginkgo biloba in 90 outpatients with cerebral insufficiency caused by old age: Results of a placebo-controlled double-blind trial, Phytomed 1 (1994) 9-16.

[24] Y. Kashihara, H. Goto, Y. Shimada, N. Sekiya, Q. Yang and K.Terasawa, Inhibitory effects of Cinnamomi cortex and cinnamaldehyde on oxygen-derived free radical-induced vasocontraction in isolated aorta of spontaneously hypertensive rats, J. Trad Med. 19 (2002) $51-57$.

[25] K. Fukuda, T. Kido, N. Miura, M. Yamamoto and Y. Komatsu, Increase in nitric oxide synthase and cyclic GMP in vascular smooth muscle cells by treatment with aqueous extracts of Astragali radix, ginsen radix and scutellariae radix, J. Trad Med. 12 (1995) 38-44. 